\title{
Article \\ Affecting Wingtip Vortex Using Wing Surface Contours
}

\author{
Sidaard Gunasekaran ${ }^{1, t, \ddagger}$, Nathan Thomas ${ }^{1, \ddagger}$ \\ 1 Assistant Professor, University of Dayton; gunasekarans1@udayton.edu \\ 2 Undergraduate Student, University of Dayton; thomasn6@udayton.edu \\ * Correspondence: gunasekarans1@udayton.edu; Tel.: +1-937-229-5345
}

\begin{abstract}
The aerodynamic efficiency of a NACA 0012 AR 4 wing was affected through periodic contours aligned in the flow direction resembling a "wrinkled" texture. Streamwise and cross-stream Particle Image Velocimetry (PIV) were conducted at the University of Dayton Low Speed Wind Tunnel (UD-LSWT) around Reynolds number of 135,000 on the NACA 0012 AR 4 wing with and without surface contours. Wings with 6 contour sections was designed by spline fitting two NACA 0012 airfoil profiles in the spanwise direction. Both 2D (wall-to-wall model) configuration and $3 \mathrm{D}$ configuration of the wings were tested to determine the effects of surface contours on the parasite and induced drag of the wing. Streamwise PIV results indicated an increase in momentum deficit in the wake of the mid-contour region due to enhanced boundary layer separation from the upper surface of the mid-contour region. The cross-stream PIV results indicated a decrease in the magnitude of azimuthal velocity, circulation and RMS quantities in the wingtip vortex with the surface contours. The reduction in the wingtip vortex properties indicates that the contours were effective in blocking the spanwise flow feeding into the wingtip vortex on the surface of the wing.
\end{abstract}

Keywords: Aerodynamic Efficiency; Wrinkled/Contoured Surface; Surface Flow

\section{Introduction}

A major inconvenience in the aerospace industry today is the fact that most conventional aircraft cannot operate under optimal conditions (maximum Lift-to-Drag ratio) because it is too slow. Two major components of drag which affects the aerodynamic efficiency are the parasitic and induced drag. The lift-induced drag is responsible for more than $70 \%$ of the total drag of the aircraft during take-off and landing and about $5-15 \%$ of the total drag during cruising [1]. By far, no universal mathematical relation exists which relates the physics and properties of the wingtip vortex rollup process, its evolution and the induced drag. Over the years, numerous methods to reduce induced drag have been conceived and implemented. Methods such as installing end plates at wingtips, winglets (most common), lift distribution tailoring (By changing the deflection of flaps on the wing), active/passive flow control methods (Blowing or Suction of air at the wingtip), etc. have been employed over the years to affect the aerodynamic efficiency of the wing. But out of all the methods mentioned above, the total reduction in drag so far has only been $5-7 \%$. The non-satisfactory performance of these methods is due to the ineffective influence of the wingtip vortex roll-up process. A recent study performed by Gunasekaran and Altman [2] has shown that there might be an interesting interaction between the parasite drag of the wing and induced drag of the wing caused by wingtip vortices. By manipulating the spanwise flow over the wing, it is hypothesized that the rollup process of wingtip vortex will be affected which changes the induced drag contribution to total drag. The research documented in this paper tests this hypothesis by contouring the surface of the wing to affect the spanwise flow. 
Wings with unintentional contouring can be found in airplanes such as light-weight sport (Ex: CGS Hawk - gross weight around 500 lbs.) which consists of multiple ribs covered by a Dacron fabric. As a result, the surface of the wings is inherently bumpy as the Dacron fabric lags between two ribs due to its own weight. In this region, the airfoil profile of the wing deviates from the intended airfoil profile. As a result, most of the wing surface doesn't have the intended airfoil profile! But, it is advertised that even without a smooth surface of the wing, the CGS Hawk light weight sport airplane delivers good performance [3].

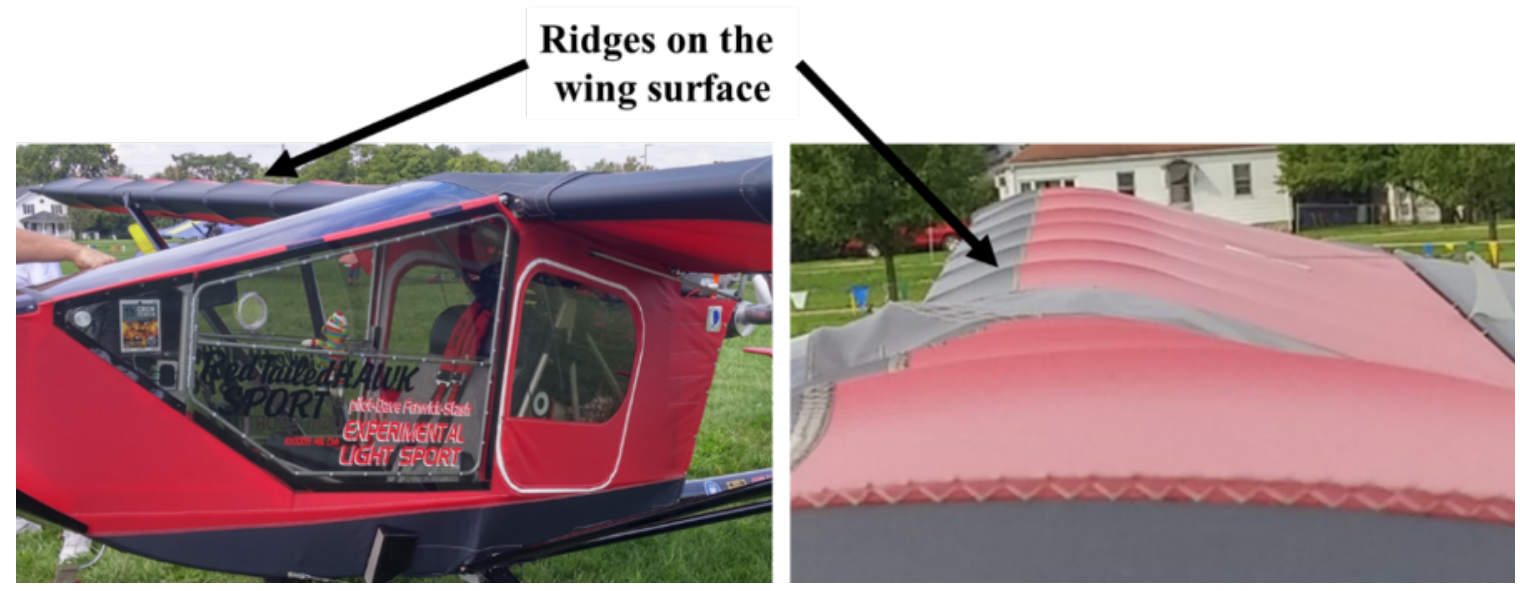

Figure 1. Front and Top View of CGS Hawk light-weight sport aircraft. It is hypothesized that the ribs act as ridges which disrupt the spanwise flow over the wings thereby increasing the efficiency.

Surface contours similar to the ones observed on the CGS Hawk (Figure 1) can also be seen on inflatable wings. One such aircraft with inflatable wings is the Woopy-Fly [4] shown in Figure 2. Ridges can be seen all over the wing surface which might affect surface flow around the wing. It is hypothesized that such ridges or bumps affects the balance of lift induced and parasite drag of the wing.

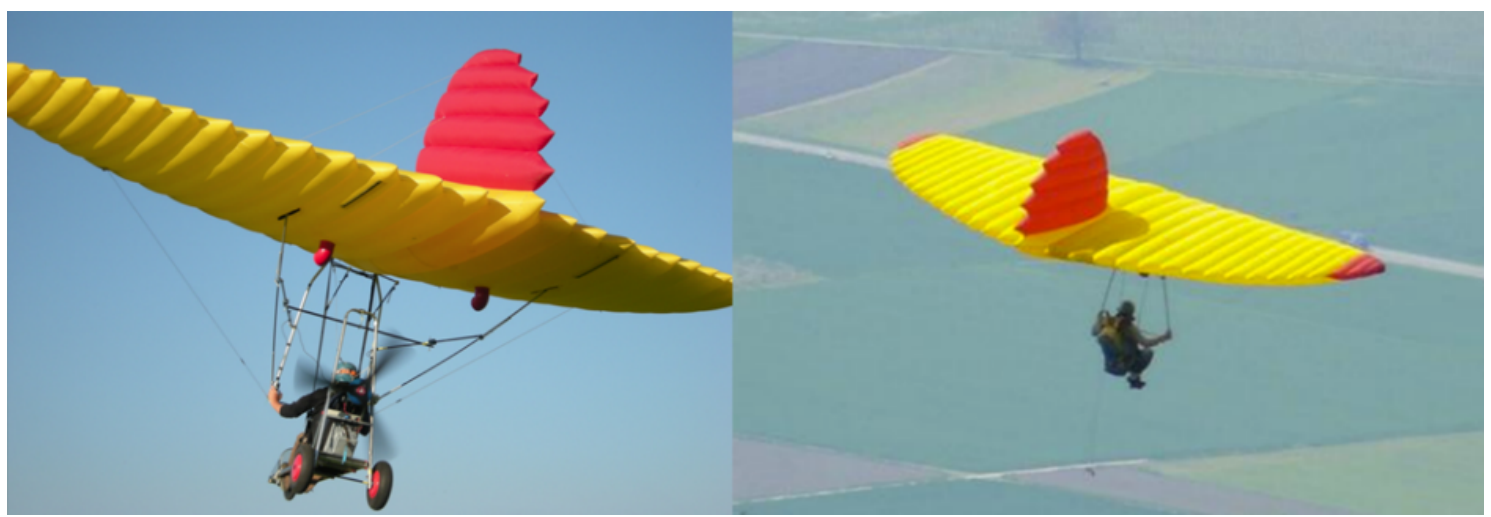

Figure 2. Woopy-Fly aircraft with inflatable wing. Similar to CGS Hawk, the inflatable wing has chordwise bumps and ridges which is hypothesized to affect the surface flow direction.

Numerous studies have been conducted concerning on the study of inflatable wings. The natural contoured shape due to inflation pockets resembles spanwise contours although unintentional. As such some very interesting, and useful data on the resultant aerodynamic efficiency of a wing without a smooth surface is available for review. A study conducted by Zhang et al [5] found a number of differences in the aerodynamic efficiency when chord-wise contours were introduced to an Eppeler 398 wing (seen in Figure 3b). Particle Image Velocimetry (PIV) and computational simulations 
were performed at low angles of attack and at multiple Reynolds numbers on a 2D wall-to-wall model and a 3D model of Eppeler 398 and NACA 4318 wings with and without surface contours. Interestingly enough, it was found that the inflatable wing noticeably reduced separation of the flow when compared to its smooth counterpart for the Reynolds number of 25000 and at an angle of attack of 4 as shown in Figure 3. However, this reduction was found to not necessarily indicate improved flight performance. The results from [5] indicates that for certain Reynolds numbers and high angles of attack, the inflatable wing had a noticeably higher aerodynamic efficiency. However, at lower angles of attack, the smooth wings were found to perform better.

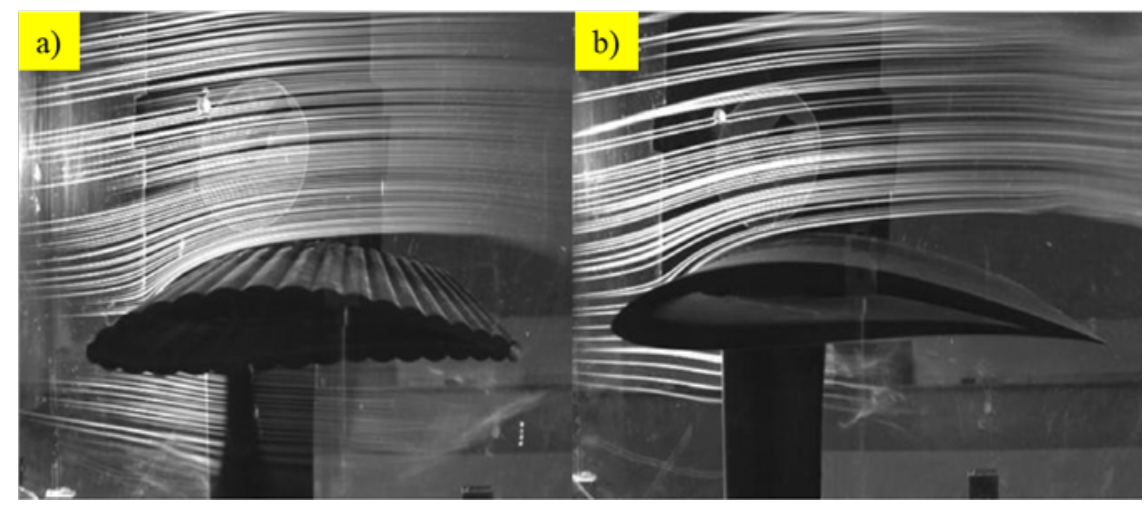

Figure 3. Flow visualization of Eppler 398 a.) bumpy b.) smooth wing at $\operatorname{Re}=25000,=4$ degrees [5]

. b

The ridges and bumps essentially increases the roughness of the surface of the wing and it has been shown through experimental investigations that the a "rough" airfoil surface will perform better than a "smooth" airfoil section at lower Reynolds numbers $(40-50,000)$ [6]. Even at high Reynolds numbers "riblets" were used to reduce frictional drag [7]. Previous experimental measurements and numerical calculations have shown a possibility of achieving up to $10 \%$ drag reduction in the total frictional drag on an immersed and textured surface [8]. Most of the concepts to increase surface roughness was inspired from biological observations such as denticles on sharks. This raised the possibility of achieving drag reduction using streamwise grooves [9], [10],[11],[12] as shown in Figure $4 \mathrm{~b}$ [13]. These streamwise grooves or riblets are proven to be effective is reducing cross-stream velocity fluctuations. The low velocity fluid flow in the valleys of the riblets produces very low-shear stresses across most of the surface of the riblets. Also, the cross-stream velocity fluctuations inside the riblet valleys were found to be much lower than the cross-stream velocity fluctuations above a flat plate [13]. The reduced cross-stream velocity fluctuations along with reduced wall shear stress results in a lower skin friction drag with riblets.

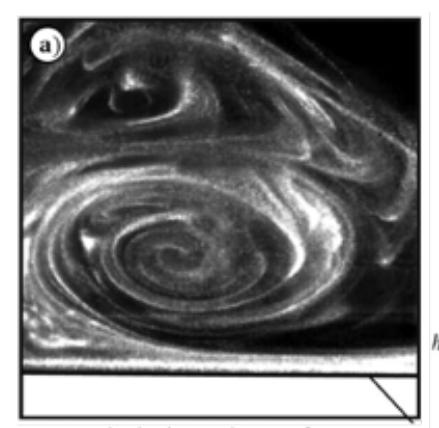

High local surface shear stress

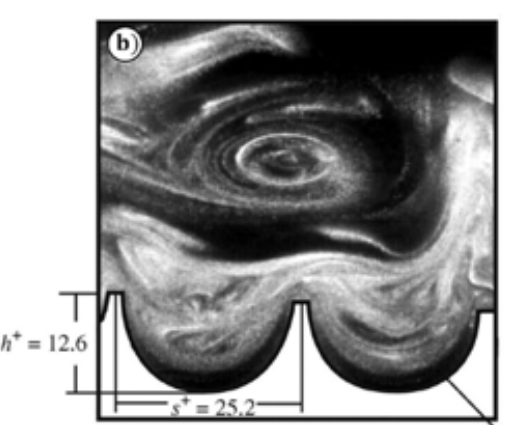

Comparatively low local shear stress

Figure 4. Turbulent flow visualization of streamwise vortices in a vertical cross section over a a) flat plate b) riblet surface [13] 
Similar to the riblets, a surface with sinusoidal wavy pattern was studied in [14] where the groves are oriented along the streamwise direction. This type of surface is also known as "wrinkled" texture. The research presented in this paper has a similar textured surface on the upper and lower surface of the wing. The wrinkled surface also was found to reduce the cross-stream fluctuations and reduces shear stress similar to riblets shown in Figure 4. The riblets with an aspect ratio close to unity gave the highest reduction in total drag [14]. The reduced cross-stream fluctuations by the riblets are highly desired in a finite wing which has an added induced drag component. With the rollup of wingtip vortices, creates a spanwise/cross-stream component of flow on the upper and lower surface of the wing. The spanwise flow feeds into the rollup of the wingtip vortices increasing the vortex strength. The riblets could act as a boundary layer fence preventing the spanwise flow that feeds into the wingtip vortex. Therefore, it is hypothesized that the properties in the wingtip vortex will be affected due to the presence of the spanwise riblets.

\section{Experimental Setup}

\subsection{Test Model}

A NACA 0012 AR 2 semispan wing was designed in SolidWorks with surface contours along the span of the wing as shown in Figure 5. The surface contours are created by a series of segments along the span of the wing. Each contoured segment is designed by having a NACA 0012 airfoil profile at the boundaries and spline fitting in-between. A total of 6 contour segments were modeled and sensitivity analysis was done on the aerodynamic forces as a function of the length and number of contoured areas. conventional NACA 0012 AR 4 wing without any surface contours was also modeled and printed.

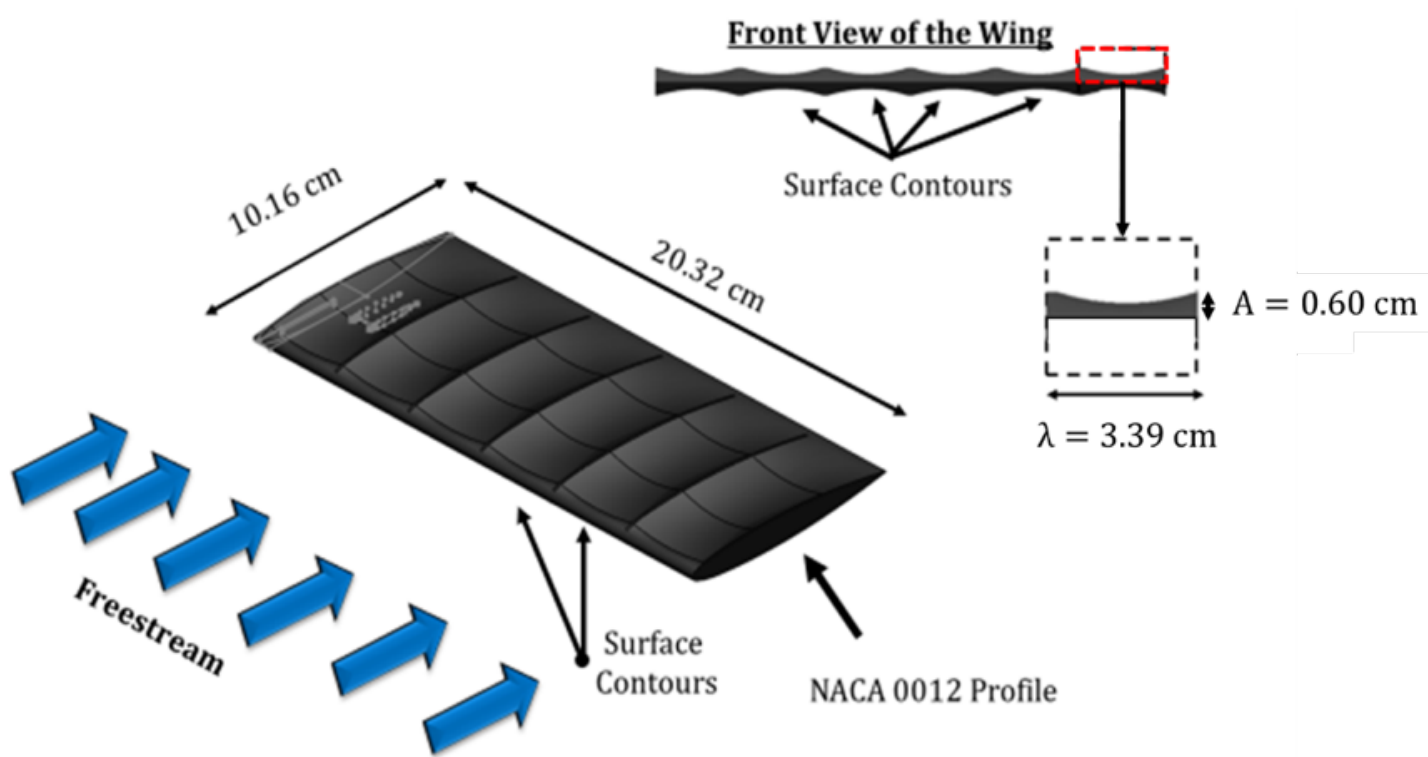

Figure 5. SolidWorks model of an AR 4 NACA 0012 wing with 12 surface contoured segments. The wing area in between each contour do not have NACA 0012 profile.

The surface area of the wing with the contours was 896.7 and the surface area of the wing without the contours was 864.5 which is a 3\% increase in surface area. The presence of contours create a variable airfoil profile between any two of the NACA 0012 profile sections. The wavelength of each contour is $3.39 \mathrm{~cm}$ and the amplitude A of each contour is $0.60 \mathrm{~cm}$. There is a $53 \%$ reduction in airfoil thickness at the mid-contour profile. The contour profile is particularly interesting in the 
midpoint section as the leading-edge mimics a cylindrical shape. The schematic of the profile sections in-between each contour segment is shown in Figure 6.

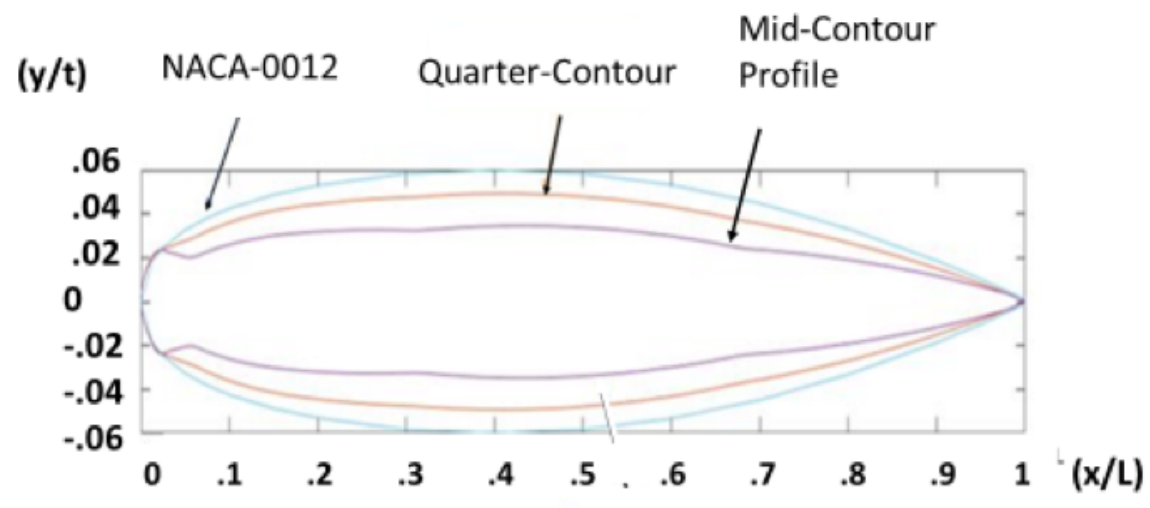

Figure 6. Profile transformation as an effect of wing contours. Profiles are plotted symmetrically on the Y-axis vs. the characteristic length.

\subsection{Wind Tunnel}

All the experiments were conducted at the University of Dayton Low Speed Wind Tunnel (UD-LSWT). The UD-LSWT has a 16:1 contraction ratio, 6 anti-turbulence screens and 4 interchangeable $76.2 \mathrm{~cm} \times 76.2 \mathrm{~cm} \times 243.8 \mathrm{~cm}\left(30^{\prime \prime} \times 30^{\prime \prime} \times 96^{\prime \prime}\right)$ test sections. The test section is convertible from a closed jet configuration to an open jet configuration with the freestream range of $6.7 \mathrm{~m} / \mathrm{s}(20 \mathrm{ft} / \mathrm{s})$ to $40 \mathrm{~m} / \mathrm{s}(140 \mathrm{ft} / \mathrm{s})$ at a freestream turbulence intensity below $0.1 \%$ measured by hot-wire anemometer. The tunnel also has the ability to vary the freestream velocity profile at up to $5 \mathrm{~Hz}$ and over $50 \%$ velocity amplitude using a downstream shuttering system. All the experiments mentioned in the paper were done in the open jet configuration where an inlet of $76.2 \mathrm{~cm} \times 76.2 \mathrm{~cm}$ opens to a pressure sealed plenum. The effective length of the test section in the open jet configuration is $182 \mathrm{~cm}(72 ")$. A $137 \mathrm{~cm} \times 137 \mathrm{~cm}\left(44^{\prime \prime} \times 44^{\prime \prime}\right)$ collector collects the expanded air on its return to the diffuser. A photo of the UD-LSWT open jet configuration is shown in Figure 7. The velocity variation for a given RPM of the wind tunnel fan is found using a Pitot tube connected to an Omega differential pressure transducer (Range: $0-6.9 \mathrm{kPa}$ ).

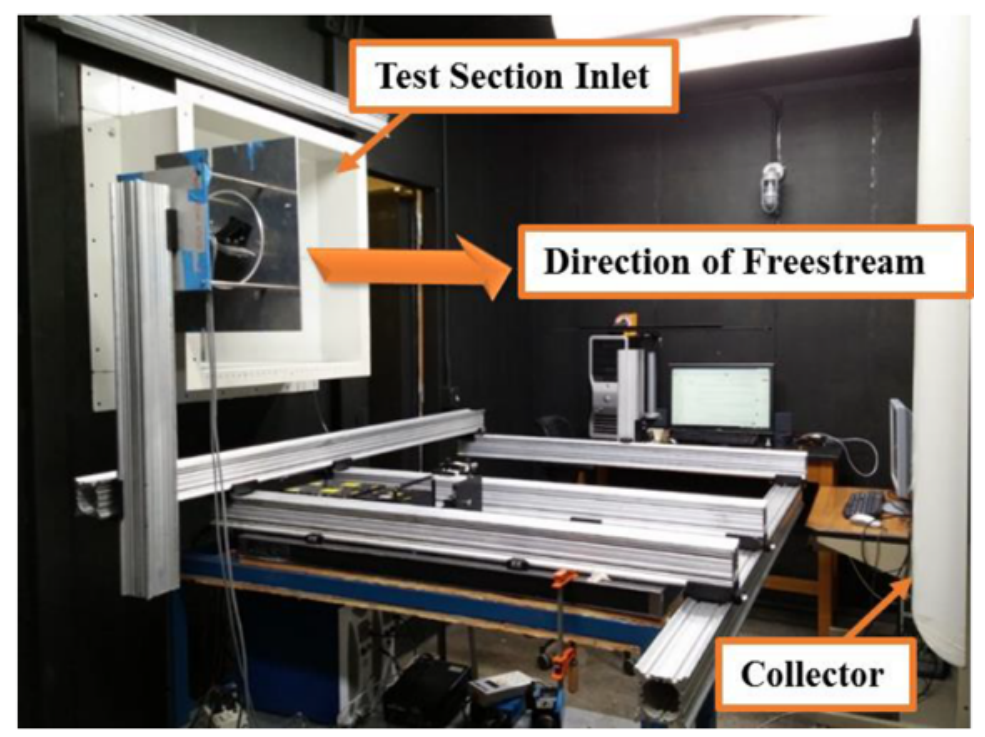

Figure 7. University of Dayton Low-Speed Wind Tunnel (UD-LSWT) in the open-jet configuration. 


\subsection{PIV Experiments}

Streamwise Particle Image Velocimetry (PIV) and cross-stream PIV were conducted in the free shear layer and the wingtip vortex of the semispan wing models with and without the holes. The PIV measurements were obtained using a Vicount smoke seeder with glycerin oil and a $200 \mathrm{~mJ} / \mathrm{pulse}$ Nd: YAG frequency doubled laser (Quantel Twins CFR 300). A Cooke Corporation PCO 1600 camera (1600 x 1200 pixel array) with a $105 \mathrm{~mm}$ Nikon lens was used to capture the images. One plano-convex lens and one plano-concave lens were used in series to convert the laser beam into a sheet. The laser and the camera were triggered simultaneously by a Quantum composer pulse generator. In each test case, over 700 image pairs were obtained and processed using ISSI Digital Particle Image Velocimetry (DPIV) software. A total of 2 iterations were performed during PIV processing with 64-pixel interrogation windows in the first iteration and 32-pixel interrogation windows in the second iteration. Both the streamwise and cross-stream PIV interrogations were conducted a Reynolds number of 135,000 . The test matrix for the PIV experiment is shown in Table 1.

Table 1. Test Matrix for Free Shear Layer (FSL) and wingtip vortex interrogation using PIV

\begin{tabular}{cccc}
\hline PIV Cases & Wing Model & Angle of Attack (Degrees) & Interrogation Location \\
\hline Streamwise FSL & Baseline and Wrinkled & $0,2,4,6,8$ & Behind TE \\
Cross-stream WV & Baseline and Wrinkled & $2,4,6,8$ & 3 Chord Lengths Downstream \\
\hline
\end{tabular}

\subsection{Streamwise PIV Setup}

The streamwise PIV was done in the FSL of the contoured wing with splitter plate on both wingtips to prevent wingtip vortex formation. The interrogation window was placed near the trailing edge of the wing as shown in Figure 8a. Two PIV interrogation regions were considered: one behind the NACA-0012 section and one behind the middle of the contour section. A Nikon $105 \mathrm{~mm}$ lens was used in the streamwise PIV case which gave a spatial resolution of $292 \mathrm{pix} / \mathrm{cm}$ in both axes. The size of the field of view was $5.5 \mathrm{~cm} \times 4.1 \mathrm{~cm}$ which gave a magnification factor of 0.21 (Figure $8 \mathrm{~b}$ ). The for the images were set to obtain an average particle displacement of 8-10 pixels in the wake of the wing. The wing model was moved in the spanwise direction to perform PIV behind the mid-contour to maintain the same magnification factor and resolution.

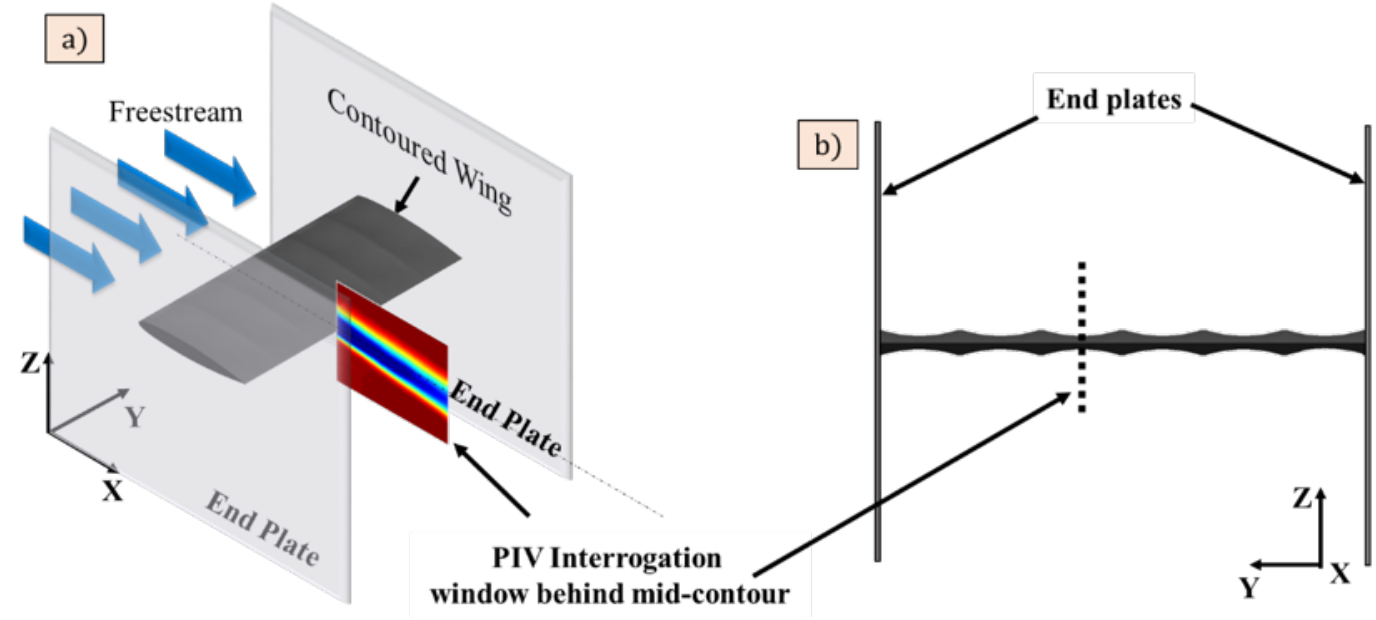

Figure 8. a) Schematic of the PIV interrogation windows in the wake of NACA 0012 wall-to-wall model b) Schematic of the PIV field of view aligned at the mid-contour in the wake of wing 


\subsection{Cross-stream PIV Setup}

The cross-stream PIV was done to determine the effects of spanwise contours on the roll-up of the wingtip vortex. The wingtip vortex from the baseline NACA 0012 and the contoured wing was interrogated at multiple angles of attack at a Reynolds number of 135,000 as mentioned in Table 1. The schematic of the cross-stream PIV setup is shown in Figure 9. The cross-stream interrogation window is 3 chord lengths downstream from the trailing edge of the wing. The PCO 1600 camera was located at more than 10 chord lengths downstream from the trailing edge of the wing, inside the collector and the effect of the camera being in the flow will comparatively be less. Due to the long object distance, a Nikon $200 \mathrm{~mm}$ with extension rings were used to focus the interrogation region. The spatial resolution of the field of view was $350 \mathrm{pix} / \mathrm{cm}$, and the size of the field of view was around 4.6 $\mathrm{cm} \times 3.4 \mathrm{~cm}$ which gave a magnification factor of 0.25 . The time delay between the laser pulses was changed at each angle of attack to obtain 8-10 particle displacement at the boundary of the wingtip vortex.

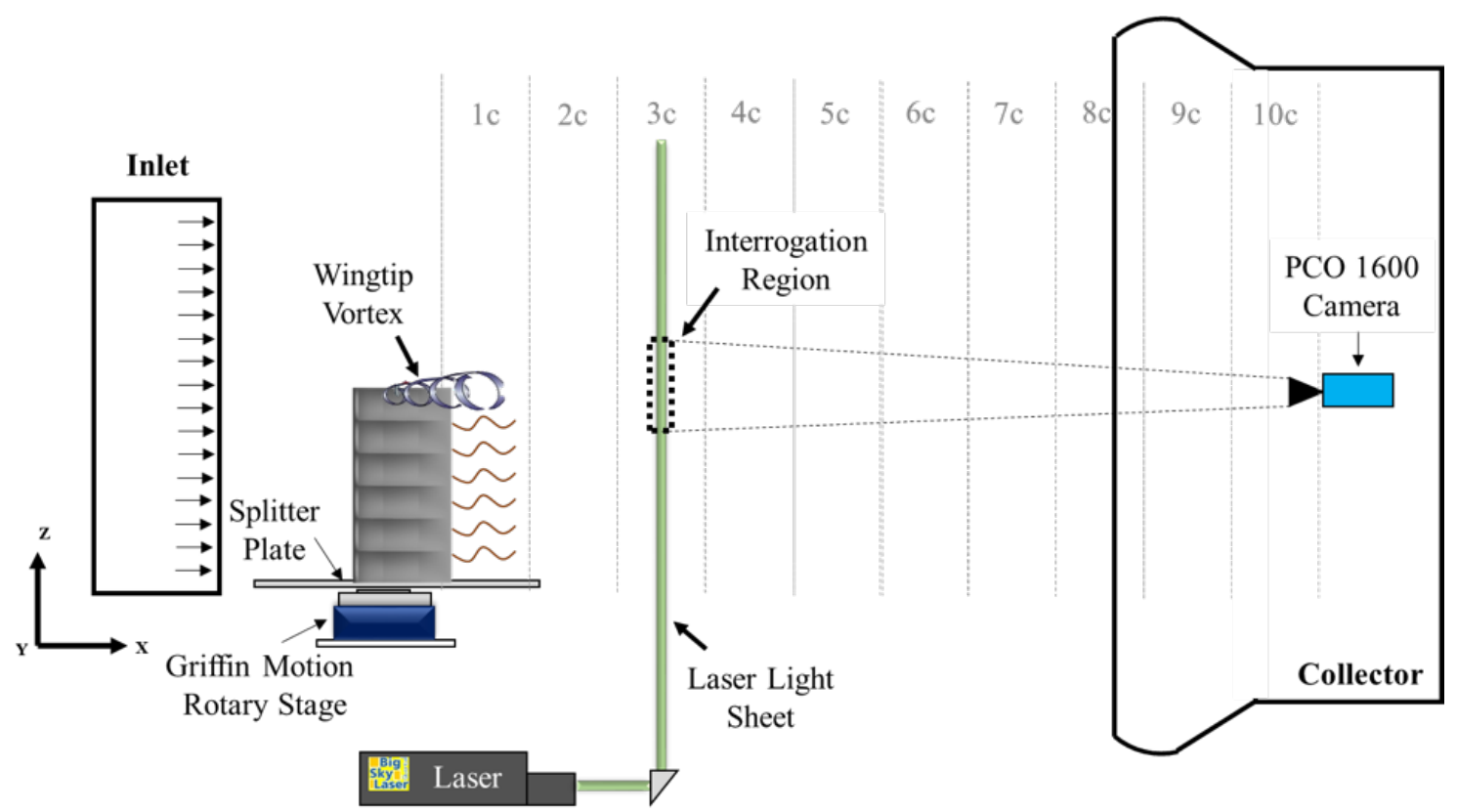

Figure 9. Schematic of cross-stream PIV setup for wingtip vortex interrogation.

\section{Results}

\subsection{Streamwise PIV Results}

The streamwise velocity Ux was determined behind the NACA-0012 wall-to-wall model (Figure 10a) and the mid-contour section (Figure 10b). It is evident from the contours that the momentum deficit behind the mid-contour profile is greater than the baseline. There is also an apparent increase in the wake half width ( - identified by the location of $99 \% U_{\infty}$ ) behind the mid-contour profiles when compared to the baseline. The wake half-width of the two cases are similar until angle of attack. The differences in the wake-half width between the two cases increases significantly at 6 and 8 angle of attack. Apart from the wake-half width, the magnitude of the Ux in the wake is comparatively lower in the mid-contour at all angles of attack. The momentum deficit profiles shown in Figure 10 helps to emphasize the difference in wake momentum deficit. The profiles were obtained by averaging 10 columns of data from the center of the field of view. The streamwise velocity is normalized by the freestream and plotted against the normalized wake-half width $\left(y / L_{0}\right)$. The momentum deficit behind the mid-contour contour is greater than all the NACA 0012 baseline angle of attack cases. The momentum deficit of the mid-contour 2 case has almost the same magnitude as the momentum 
deficit of the baseline at 8 case. The increased momentum deficit for a thin mid-contour profile might be due to the separation of the boundary layer from the upper surface of the wing.

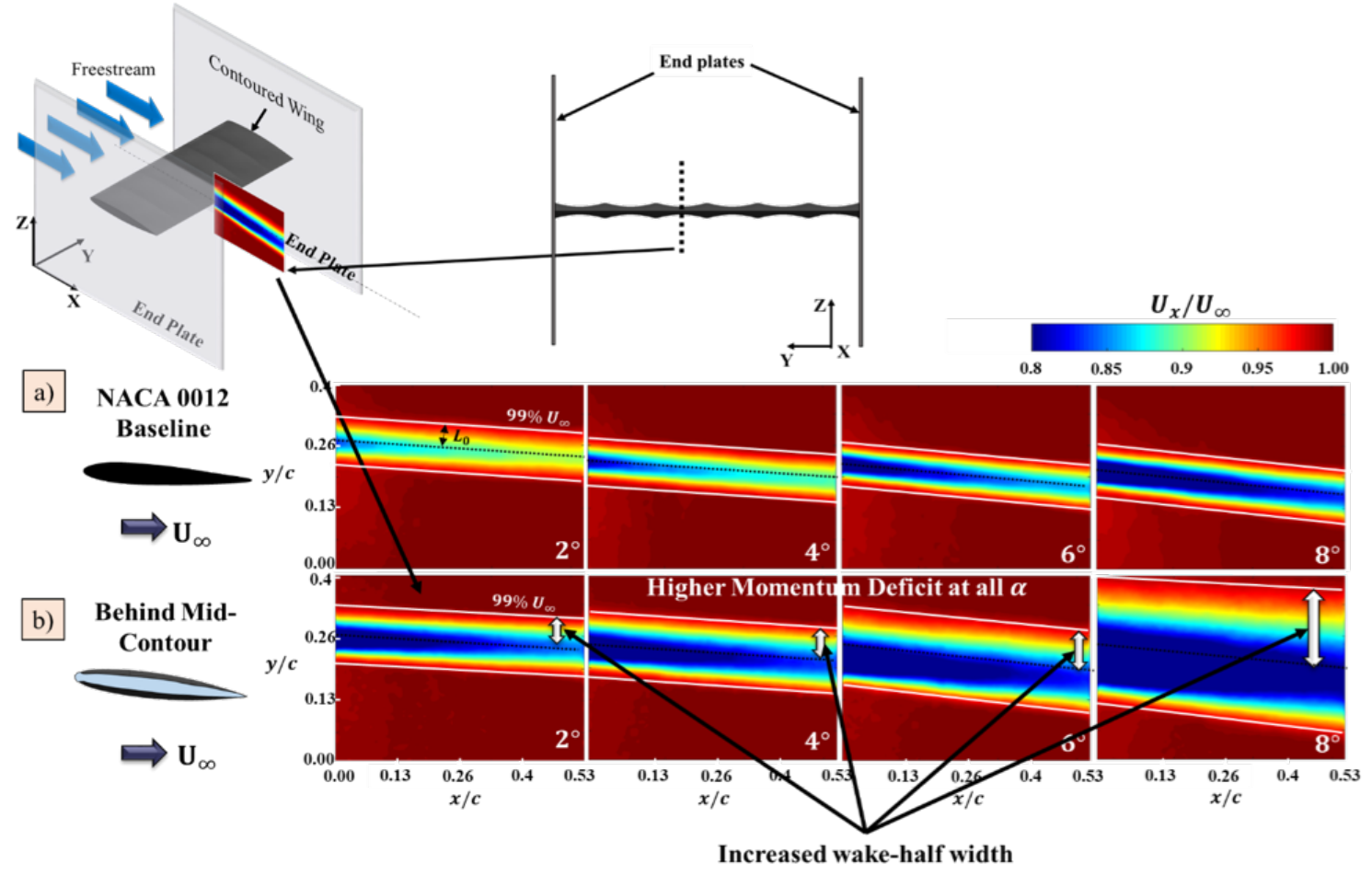

Figure 10. Normalized streamwise contours in the FSL wake of a.) Baseline NACA 0012 wall-to-wall model and b) Behind mid-contour of the contoured wing wall-to-wall model. The momentum deficit and the wake half-width behind mid-contour is greater at all angles of attack when compared to the baseline.

The momentum deficit profiles shown in Figure 11a was used to determine the sectional drag coefficient of the NACA 0012 baseline profile and the mid-contour profile. The sectional drag coefficient was found by integrating the momentum deficit profiles according to the equation,

$$
C_{D}=\frac{\rho U_{\infty}^{2}}{q_{\infty} S} \int \frac{U_{x}}{U_{\infty}}\left(1-\frac{U_{x}}{U_{\infty}}\right) d y
$$

where is the density of the fluid, is the freestream velocity, is the reference area of the wing, and is the dynamic pressure the experiment was conducted at. Equation 1 was obtained from the momentum equation assuming steady, inviscid and incompressible flow with no body force and no streamwise pressure gradient. The sectional drag coefficient for both cases increases non-linearly with angle of attack. But the magnitude of the drag coefficient behind the mid-contour profile is significantly larger than the baseline NACA 0012 profile. Even though the normalized momentum deficit profiles in Figure 11a shows similar trend in both cases, the wake-half width is significantly larger in the mid-contour case as seen in Figure 10b. At 8 angle of attack, the streamwise velocity contours shows a significant increase in wake-half width when compared to all the other angles of attack. Therefore, the drag coefficient of the mid-contour profile at 8 also shows a significantly higher magnitude when compared to the baseline. It is very likely that the drag coefficient of the sections in-between the mid-contour and the NACA 0012 profile lies within the differences in the drag coefficient magnitude seen in Figure 11b between the two cases. In order to determine the effect of increased momentum deficit in the wingtip vortex, the cross-stream PIV results are analyzed in the next section. 


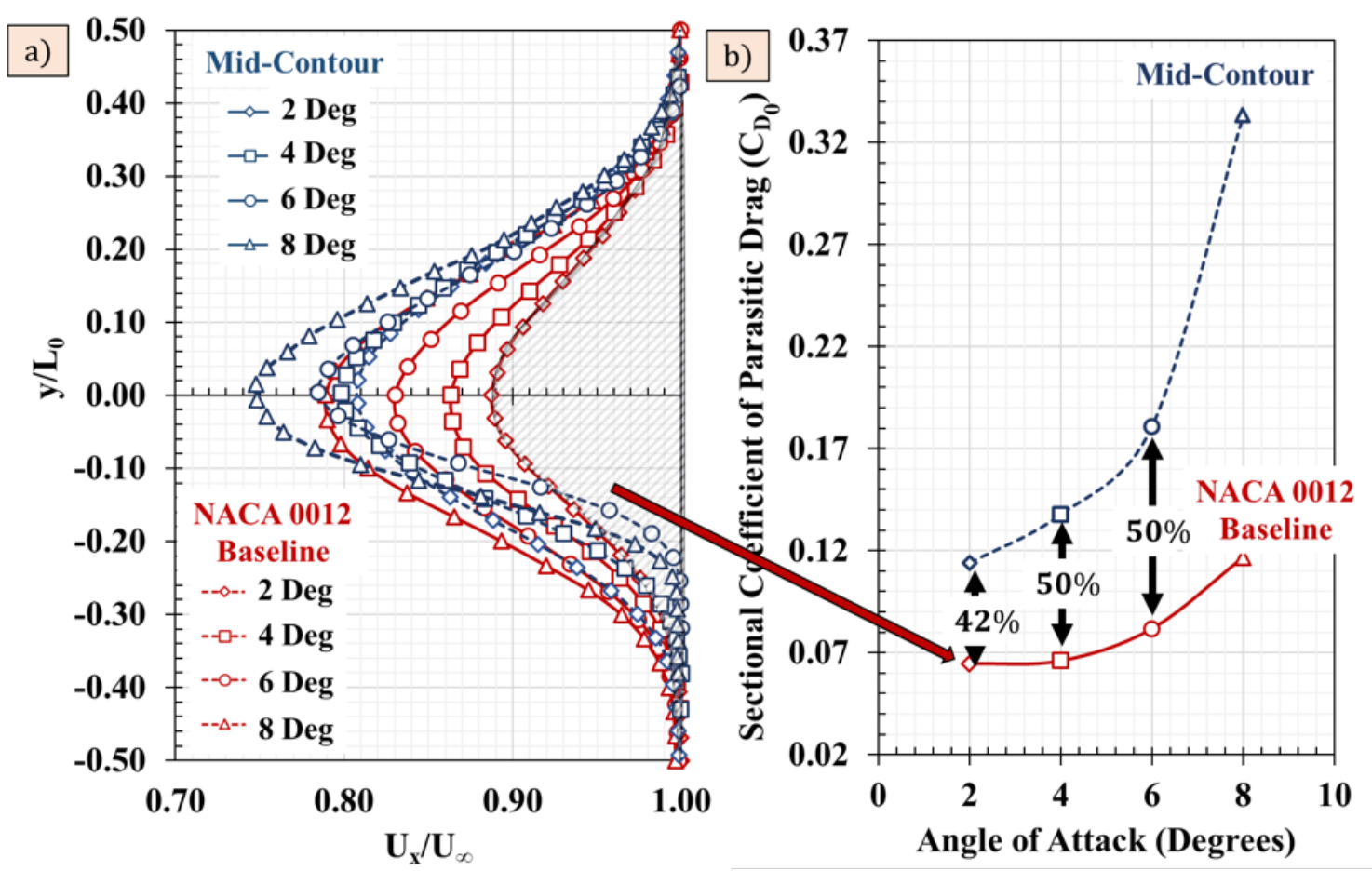

Figure 11. a) Momentum deficit profiles taken from contours shown in Figure 10 for the baseline and the mid-contour case at different angle of attack. The profiles indicate a significant increase in the momentum deficit at all angles of attack when compare to the baseline. b) Sectional parasitic drag coefficient variation with angle of attack for the two cases. The $\mathrm{Cd}$ is much greater behind the mid-contour profile when compared to the baseline at all angles of attack.

\subsection{Wingtip Vortex Results}

The intention behind the contoured wing is to determine the effect of the contours on the wingtip vortex properties. The contours acting like a riblet were hypothesized to block the spanwise flow over the wing thereby reducing the strength of the wingtip vortex. The properties of the wingtip vortex are discussed in this section starting with the wingtip vortex wandering. It is important to quantify the vortex wandering since increased level of vortex wandering biases the mean velocity component to be lower than the actual value. It also makes the appearance of a larger vortex. The vortex wandering was quantified by tracking the center of the vortex across all individual image pairs. The center of the vortex was identified through scaled Q-criterion. The Q-criterion is a well-known method to identify vortices in a flowfield. The equation for Q-criterion is,

$$
Q=\frac{1}{2}\left(\|\Omega\|^{2}-\|R\|^{2}\right)
$$

where $\|\Omega\|$ is the absolute magnitude of vorticity given by

$$
\Omega=\frac{1}{2}\left(\frac{\partial U_{z}}{\partial y}-\frac{\partial U_{y}}{\partial z}\right)
$$

and $\|R\|$ is the absolute magnitude of strain rate given by

$$
R=\frac{1}{2}\left(\frac{\partial U_{z}}{\partial y}+\frac{\partial U_{y}}{\partial z}\right)
$$


The scaled Q-criterion $\left(Q_{s}\right)$ is the shear strain normalized $Q$-criterion,

$$
Q_{s}=\frac{1}{2}\left(\frac{\|\Omega\|^{2}}{\|R\|^{2}}-1\right)
$$

An example plot of the normalized Q-criterion of the contoured wing case at 4 angle of attack is shown in Figure 12. The maximum Q-criterion was identified as the center of the wingtip vortex at each instantaneous image pairs. The vortex centers identified through this method is shown in Figure 13 for 6 angle of attack for both the baseline NACA 0012 and the contoured wing.

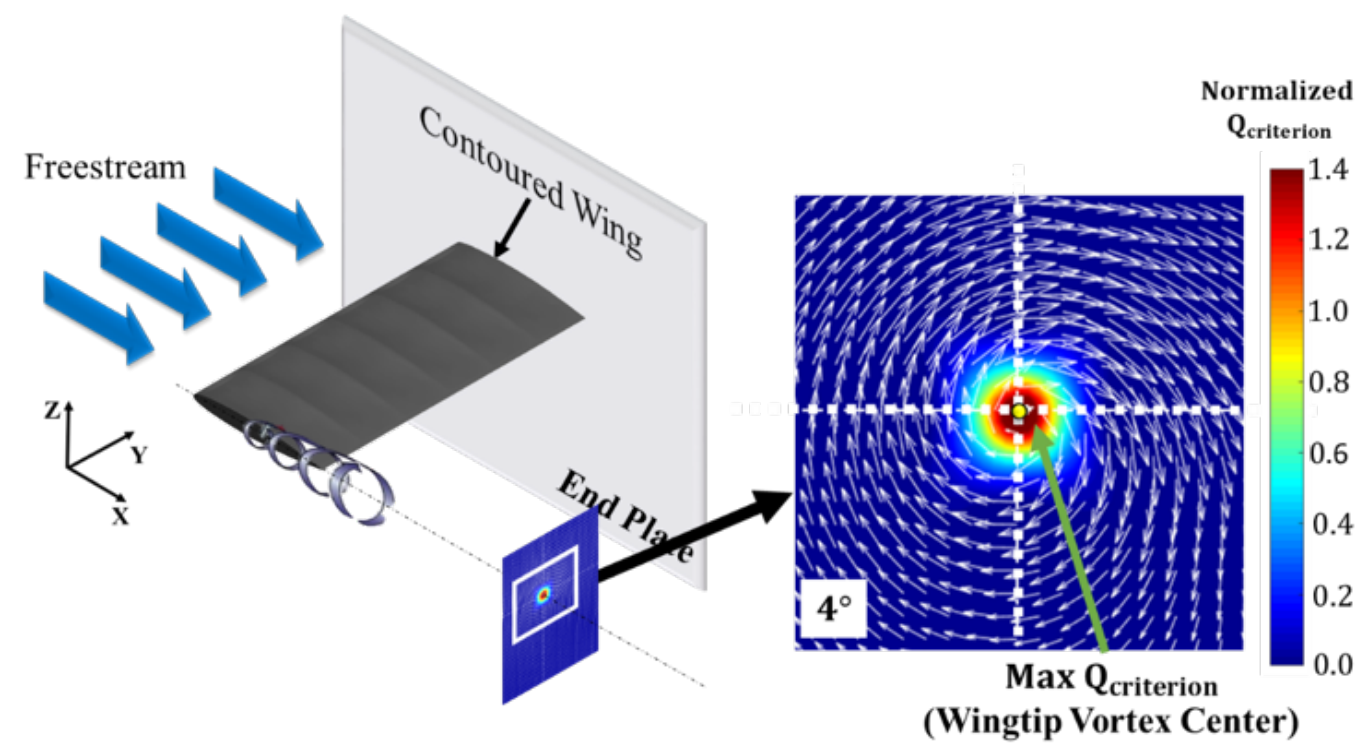

Figure 12. Using scaled Q-criterion to determine the vortex center at each individual image pairs to quantify vortex wandering.

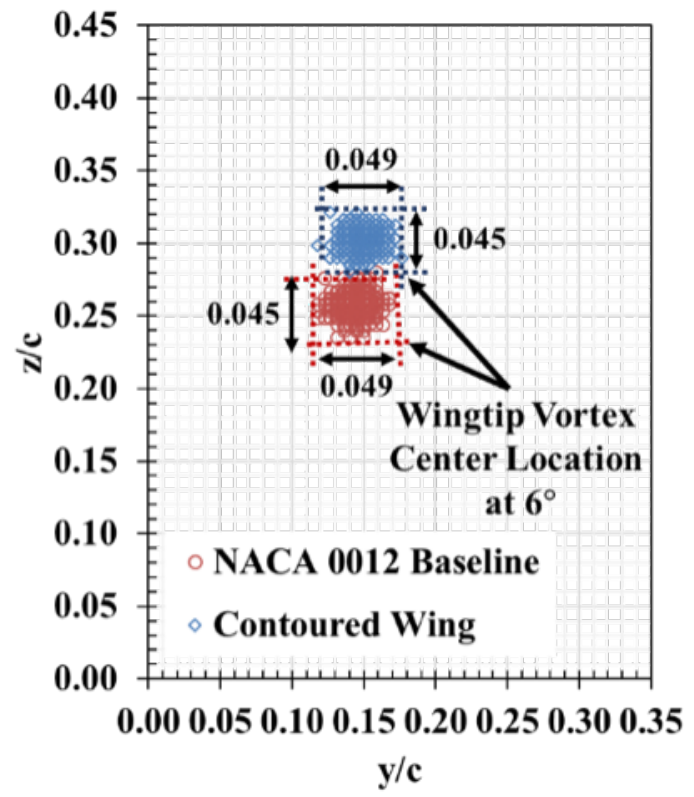

Figure 13. Wingtip vortex wandering for NACA 0012 baseline and the contoured wing at 6 angle of attack. 
Figure 13 clearly shows the variation of the vortex center location for all 700 image pairs captured for both cases at 6 angle of attack. The wandering of the vortex center for both cases was contained within the $5 \%$ chord which is less than $5 \mathrm{~mm}$. Therefore, significant deviations of the vortex center are not observed. The vortex wandering was corrected by centering all the vortex center at a single location. The resultant deviations in the peak Uz and Uy azimuthal velocities were less than $5 \%$. Whereas higher percentage differences between the baseline and the contoured wing were seen in the azimuthal velocity contours shown in Figure 14.

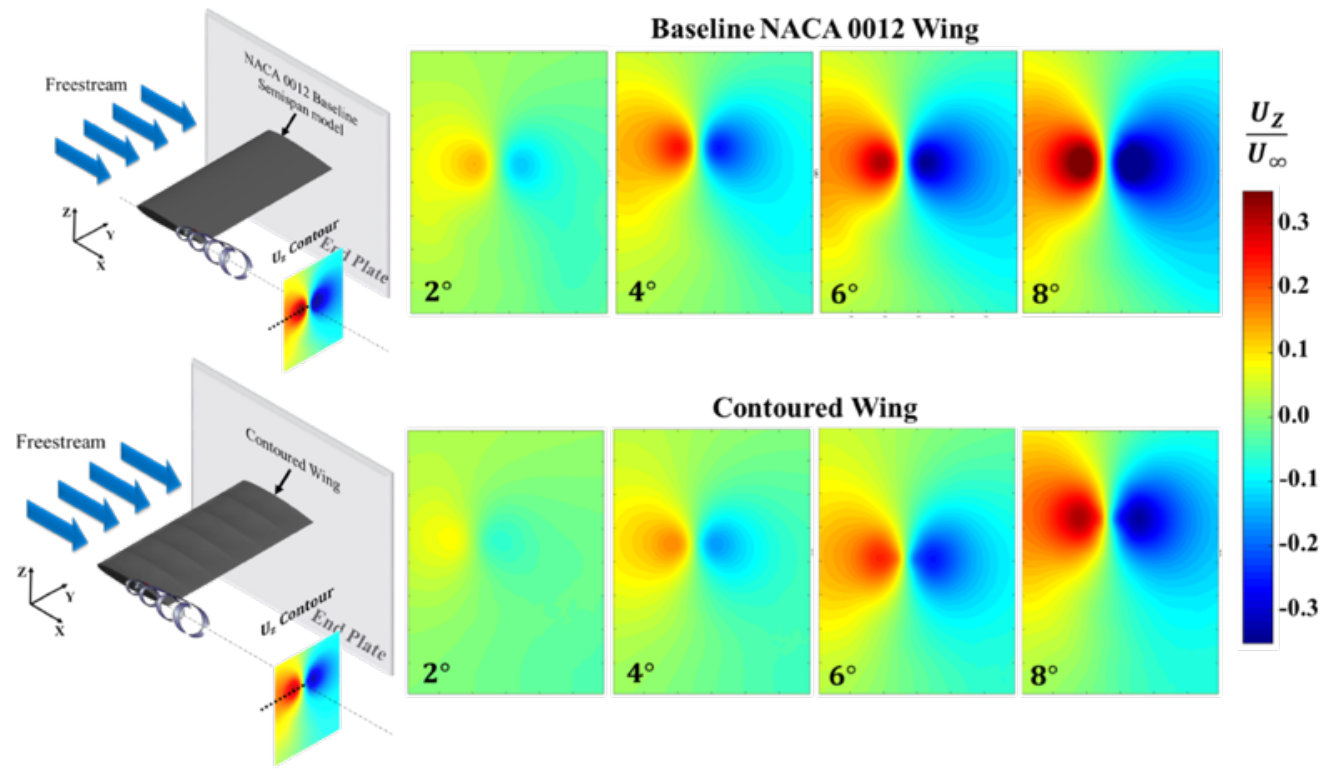

Figure 14. Variation of azimuthal velocity for a.) baseline NACA 0012 wing b.) contoured wing for different angles of attack. The magnitude of the azimuthal velocity of the contoured wing is lower than the baseline for all angle of attack.

The magnitude of the peak azimuthal velocity increases with increase in angle of attack for both cases as expected. The positive contour of the $\mathrm{Uz}$ velocity indicates the wingtip vortex rolling up from the free shear layer into the wingtip vortex (can be seen clearly in vorticity plot (Figure 16)). The magnitudes of the azimuthal velocities in the contoured wing case are lower than the baseline case at all angles of attack indicating that the cross-stream momentum of the wingtip vortex is reduced by the presence of the contours. This decrement in the azimuthal velocity could be due to contours inhibiting the spanwise flow that feeds into the wingtip vortex. The differences in the azimuthal velocity can be clearly seen by obtaining profiles from the contours as shown in Figure 15a. The normalized azimuthal velocity profiles in Figure 15a are taken horizontally parallel to the wingspan and hence the free shear layer. The azimuthal velocity profiles are plotted against the wingtip vortex radius normalized by the radius of the vortex boundary. The vortex boundary is identified as the location at which the maximum azimuthal velocity occurs. The contoured wing profiles clearly show a decrement in the azimuthal velocity profile when compared to the baseline at all angles of attack. The differences between the baseline and the contoured wing cases in the azimuthal velocity are preserved on the positive and negative side of the profile indicating that the vortex is nearly symmetric and the influence of the free shear layer on the wingtip vortex is minimal. The azimuthal velocity of the contoured wing at 8 angle of attack has the same magnitude as the 6 angle of attack of the baseline case. The peak azimuthal velocity is also plotted against the angle of attack for both the cases in Figure 15b. A nearly linear variation in the azimuthal velocity profiles can be seen in both the cases as shown by the linear regression equation. The differences in the peak azimuthal velocity is greater at lower angles of attack and decreases as the angle of attack increase. At 2 there seems to be 
232

233 234

a $43 \%$ reduction in the magnitude of the peak azimuthal velocity when compared to the baseline and at, only $6 \%$ reduction is observed. The reduction could be due to the ineffectiveness of the ridges at higher angles of attack preventing the spanwise flow.
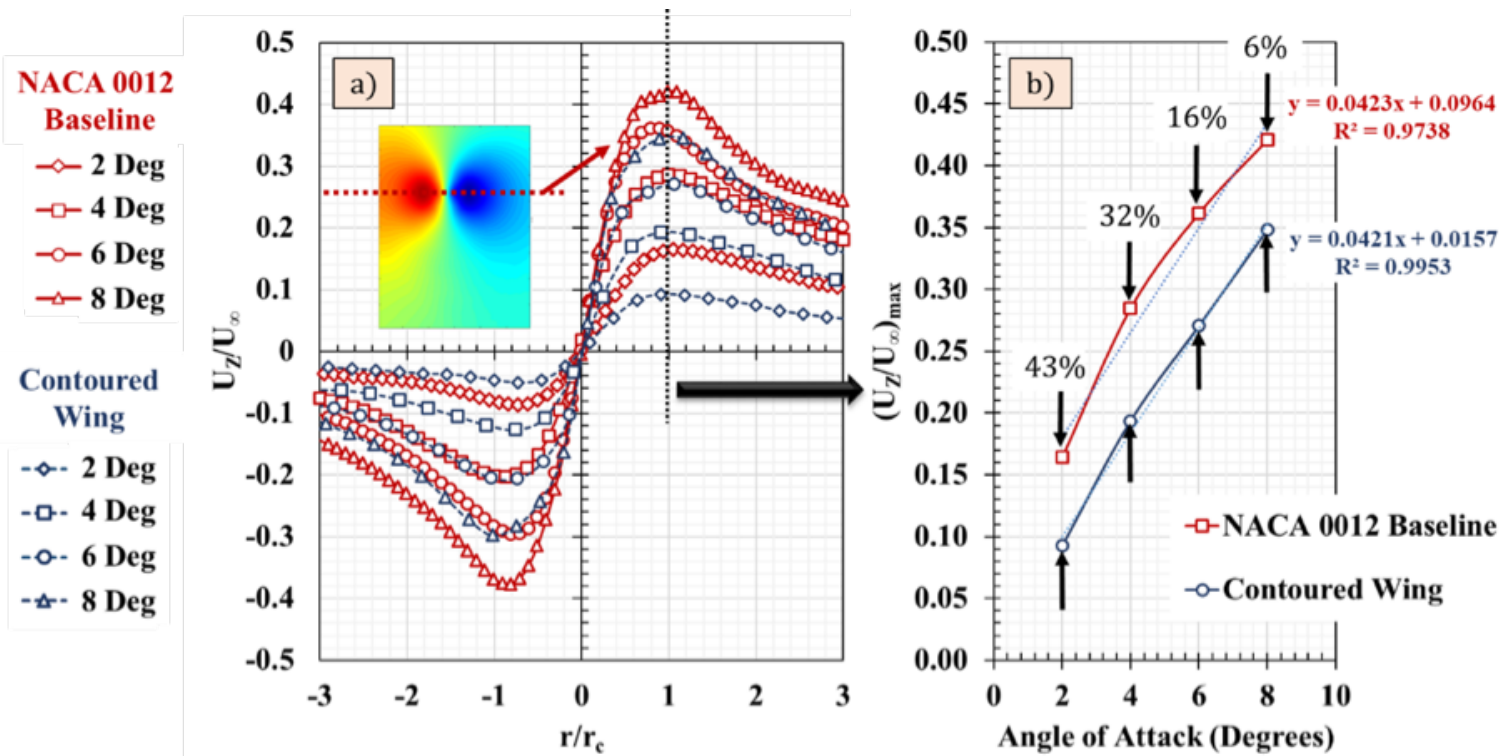

Figure 15. a) Normalized Azimuthal velocity profiles of baseline and contoured wing for varying angles of attack. b) Peak azimuthal velocity measured on horizontal line passing through vortex centers.

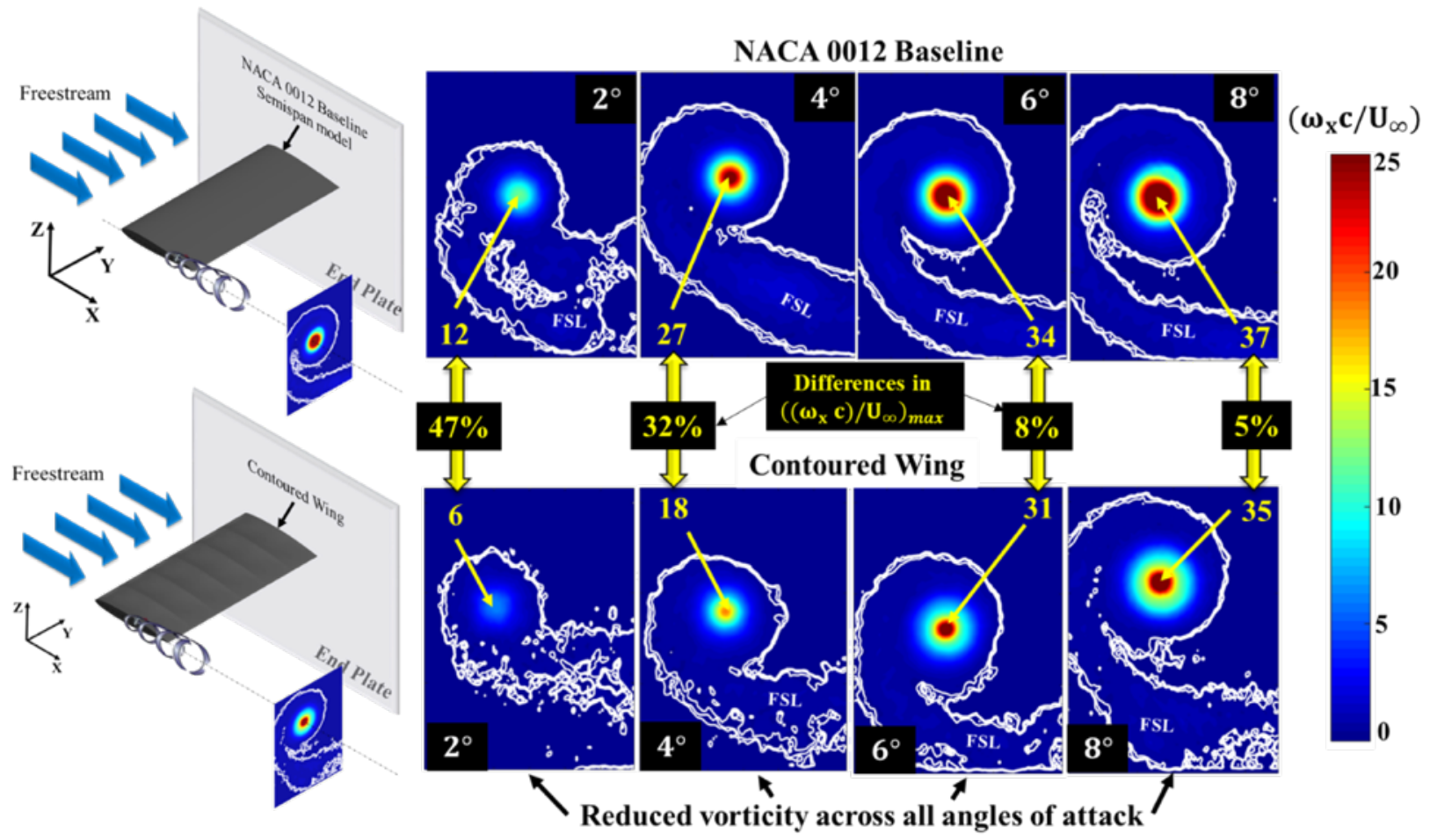

Figure 16. Comparison of normalized $x$-vorticity contours for NACA-0012 baseline and contoured configurations. Differences shown indicate that contours altered the wingtip roll-up process. Results help to corroborate finding by Gunasekaran and Altman (2017). 
According to Batchelor's model (Batchelor (1964) (), any change in the peak azimuthal velocity will result a change in the radius of the wingtip vortex provided that the circulation remains the same. To quantify the changes in the circulation between the two cases, $x$-vorticity of the wingtip vortex was calculated using Equation 3. The velocity gradients in Equation 3 was determined using the central difference technique. The normalized $x$-vorticity contours for the baseline and the contoured wing is shown in Figure 16.

The vorticity magnitude is higher at the wingtip vortex core as expected and increases with angle of attack for both the cases. However, the contoured wing case show a lower vorticity magnitude on comparison with the baseline across all angles of attack. This effectively indicates that the contours on the surface of the wing effectively altered the rollup process of the wingtip vortex. The normalized $\mathrm{x}$-vorticity values of $0.15,0.20$ and 0.30 are highlighted in white to indicate the presence of the free shear layer (FSL) in all angles of attack for both cases. A clear distinction between the wingtip vortex and the free shear layer which rolls up into the vortex can be seen. It was postulated in Gunasekaran and Altman [2] that the free shear layer interacts with the wingtip vortex rollup process at lower angles of attack and moves away from the wingtip vortex as the downwash increases at higher angles of attack. Figure 16 indicates similar behavior where the distance between the wingtip vortex core and the free shear layer increases with increase in angle of attack for both the baseline and the contoured wing cases.

To quantify the reduction in the wingtip vortex strength, wingtip vortex circulation was determined by integrating the vorticity as shown in Equation 6 .

$$
\Gamma=\iint \omega \cdot d s
$$

where $\Gamma$ is the circulation, $\omega$ is the vorticity and $d s$ is the incremental surface area. After determining the wingtip vortex center through Q-criterion, several concentric circles were made around the vortex center to determine the circulation as a function of wingtip vortex radius. An example of a circulation plot obtained through this procedure is shown in Figure 17.
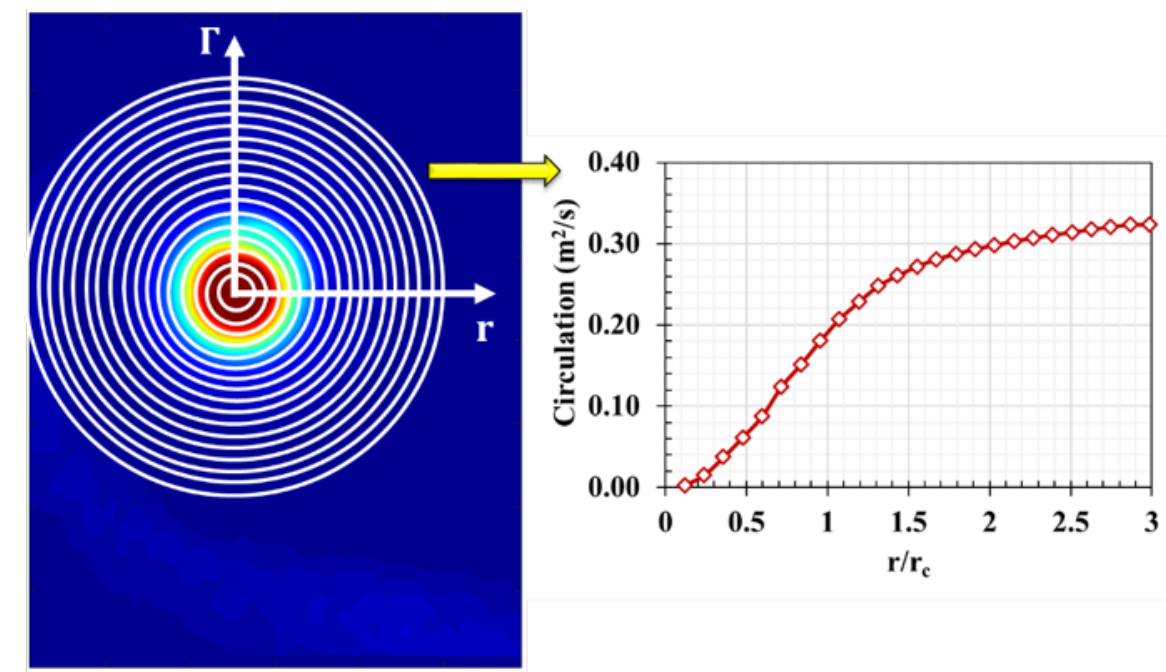

Figure 17. Variation of circulation as a function of vortex radius. The circulation was determined by taking concentric circles from the vortex center.

Once the circulation variation is obtained, the profile is fitted to an ideal Lamb-Oseen vortex model described by Equation 7 to determine the total circulation $\Gamma_{0}$ and vortex core radius $r_{c}$.

$$
\Gamma(r)=\Gamma_{0}\left(1-\exp \left(\frac{-r^{2}}{r_{c}^{2}}\right)\right)
$$


This method of finding circulation was developed by Stevens (2013) and has been employed in Corkery and Babinsky (2017) and Stevens and Babinsky (2017) to determine circulation of vortices emanating from pitching and plunging wings. The Lamb-Oseen model is fitted with the experimental data for the baseline NACA 0012 wing at 8 degree angle of attack by changing the total circulation value $\left(\Gamma_{0}\right)$ (Figure 18). A value of $0.3 \mathrm{~m}^{2} / \mathrm{s}$ gave the highest $R^{2}$ value of 0.98 . Similar fit was obtained for all angles of attack by changing $\Gamma_{0}$ the that gives a higher $R^{2}$ value for both the baseline and the contoured wing case. The average $R^{2}$ value for all the cases was 0.98 .

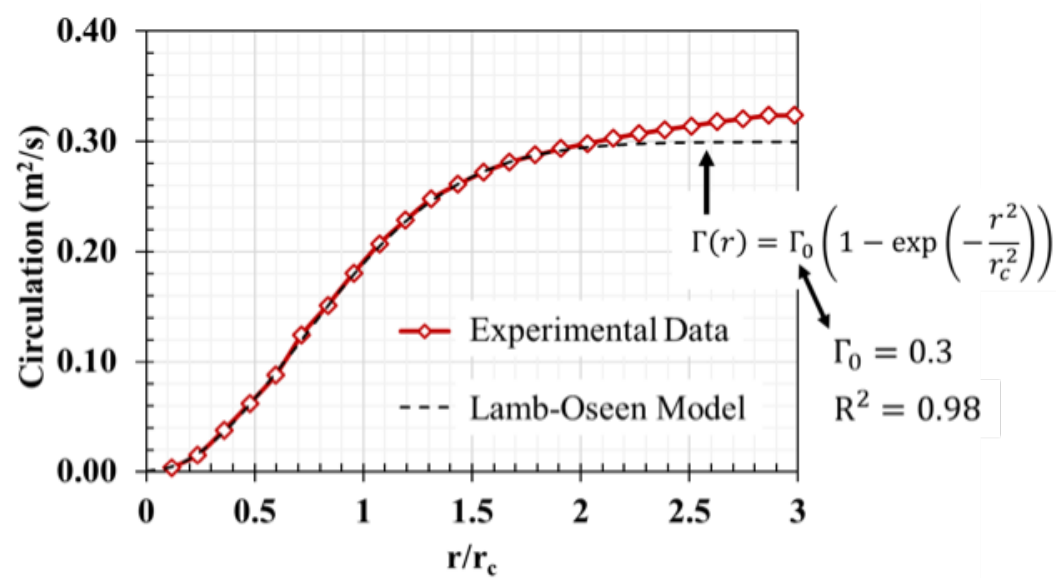

Figure 18. Determining total circulation of the wingtip vortex by fitting the experimental data with the Lamb-Oseen vortex model. The current graph is for the baseline NACA 0012 wing at $8^{\circ}$ angle of attack.

The normalized circulation obtained by this method for all angles of attack is shown in Figure 19 for the NACA 0012 baseline wing and the contoured wing. The circulation increases linearly (as denoted by the $R^{2}$ values) as a function of angle of attack for both cases. This is expected as the variation of the lift coefficient with angle of attack is also linear for both cases at the range of angle of attack shown. The magnitude of the circulation however is different between the both cases. The contoured wing case circulation magnitude is lower than the baseline wing across all angles of attack. The differences in the circulation however decreases with increase in angle of attack from $34 \%$ at $2{ }^{\circ}$ to $6 \%$ at $8^{\circ}$ angle of attack. Similar trend is seen in the peak azimuthal velocity as a function of angle of attack (Figure 15b). The average reduction in circulation across angles of attack however is around $20 \%$ between the baseline and the contoured wing. This result once again indicates that the ridges on the contoured surface of the wing reduced the strength of the wingtip vortex. 


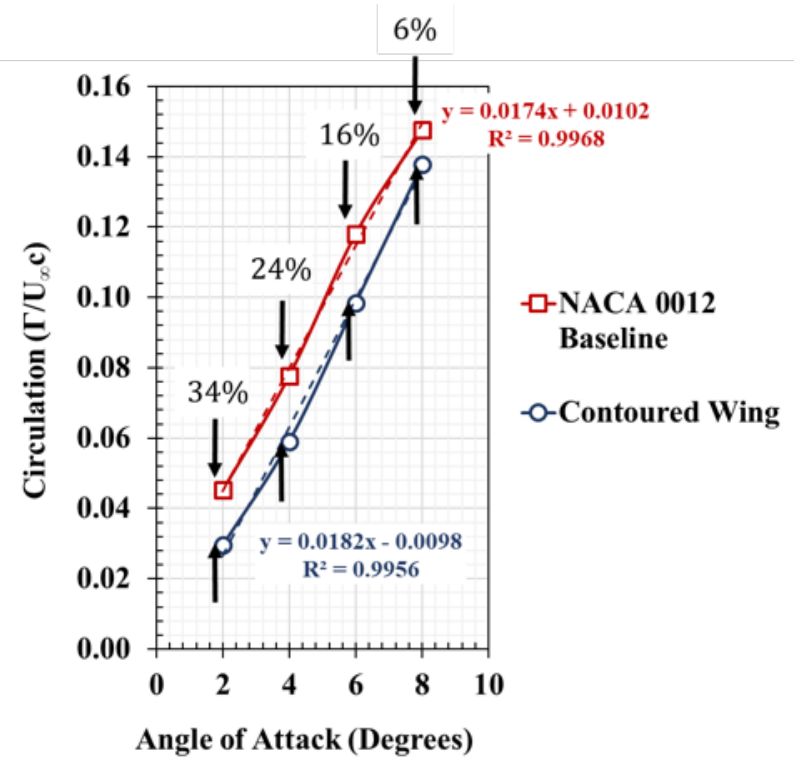

Figure 19. Peak circulation as a function of angle of attack.

Figure 16 showed disturbances in the vorticity of the free shear layer in the contoured case. This could occur due to the increased turbulence level in the free shear layer caused by the presence of the surface contour. To quantify the effect of fluctuating quantities in the wingtip vortex, the normalized $U_{Z R M S}$ was determined for both the baseline and the contoured wing case. The $U_{Z R M S}$ represents the fluctuations in velocity about the $Z$-axis which is perpendicular to the span of the wing. The $U_{Z R M S}$ is calculated by,

$$
U_{Z R M S}=\sqrt{\overline{\left(u_{z}^{\prime}\right)^{2}}}
$$

where $u_{z}^{\prime}$ is the fluctuating velocity about the Z-axis. In the baseline case, higher $U_{Z R M S}$ is concentrated in the wingtip vortex core when compared to the $U_{Z R M S}$ in the free shear layer and in the boundary of the vortex (Figure 20). In the contoured wing case however, the magnitude of $U_{Z R M S}$ is distributed throughout the vortex. However, the concentration of the $U_{Z R M S}$ in the vortex center is comparatively reduced in the contoured wing case. The normalized $U_{Z R M S}$ values of and are highlighted in white to distinctly observe the wingtip vortex and the FSL. A distinct separation is seen between the wingtip vortex and the FSL in both the cases at the wingtip vortex-FSL interface in Figure 20. The $U_{Z R M S}$ at this interface is lower than the wingtip vortex and the FSL which could potentially indicate the separation from the wingtip vortex and the free shear layer. The $U_{Z R M S}$ in the free shear layer is increased in the contoured wing when compared to the baseline wing due to the higher momentum deficit observed in Figure 10. 


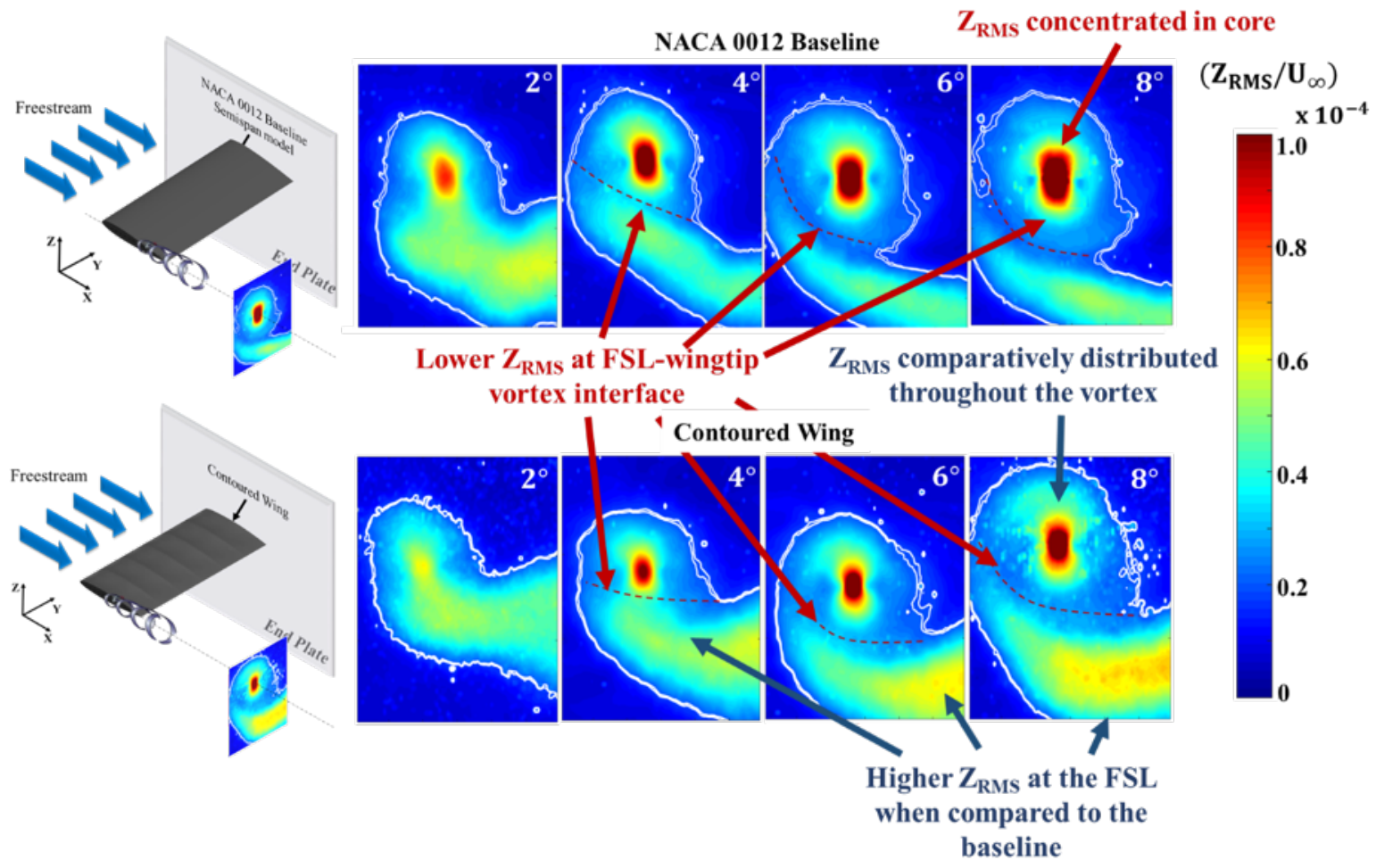

Figure 20. The ZRMS plot shows the contoured wing having a lower ZRMS in its core. However, the increased FSL vortex-core interaction may be clearly noted for the contoured wing case. At 4 there is lower ZRMS measured at the FSL-vortex interface which may indicate separation between the FSL and the wingtip vortex.

\section{Conclusions}

A NACA 0012 semi-span wing with contours resembling "wrinkled" texture was investigated to determine the changes in the free shear layer and the wingtip vortex. The semi-span wing features 6 contours which were hypothesized to reduce the spanwise flow component over the wing which feeds into the wingtip vortex. The important results are as follows:

- Larger momentum deficit along with larger wake half width was observed in the free shear layer in the wake of the mid-contour section when compared to the baseline. The average increase in the momentum deficit was around $8 \%$ excluding the 8 angle of attack. The momentum deficit was significantly greater at 8 angle of attack due to boundary layer separation. This is a consequence of a higher sectional drag coefficient caused by separation effects at lower angles of attack for the mid-contour profile shape. The increased drag coefficient in the contoured wing is due to the presence of a round leading edge causing separation at lower angle of attack.

- Even though the momentum deficit increased in the free shear layer in the contoured wing case, the peak azimuthal velocity of the wingtip vortex was measurably lower than the baseline ( $43 \%$ at 2 ranging up to $6 \%$ at 8 ) at all angles of attack.

- The peak vorticity at the wingtip vortex core decreased from $47 \%$ at 2 to $5 \%$ at 8 angle of attack in the contoured wing case when compared to the baseline. This indicates that the rollup of the wingtip vortex was affected by the presence of the contours.

- The overall circulation of the wingtip vortex also reduced in the contoured wing case by an average of $20 \%$ across all angles of attack when compared to the baseline.

- The contoured wing case shows increased ZRMS in the FSL feeding into the wingtip vortex. However, the core of the contoured wing vortex has a lower ZRMS value when compared to the baseline. 
Conflicts of Interest: The authors declare no conflict of interest.

\section{Abbreviations}

The following abbreviations are used in this manuscript:

$\alpha$ - Angle of Attack (Degrees)

AR - Aspect Ratio

$c$ - Chord Length (m)

$\Gamma(r)$ - Circulation as a function of vortex radius $\left(\mathrm{m}^{2} / \mathrm{s}\right)$

$C_{D}$ - Coefficient of Drag

$C_{D 0}$ - Coefficient of Sectional Drag

$q_{\infty}$ - Dynamic pressure $\left(N / m^{2}\right)$

$u_{y}^{\prime}$ - Fluctuating Velocity in Y-axis $(\mathrm{m} / \mathrm{s})$

$u_{z}^{\prime}$ - Fluctuating Velocity in Z-axis $(\mathrm{m} / \mathrm{s})$

$U_{\infty}$ - Freestream velocity $(\mathrm{m} / \mathrm{s})$

$\eta$ - Non-dimensional vortex radius

$\sigma_{y}$ - RMS wandering amplitude component in y-axis $(m)$

$\sigma_{z}$ - RMS wandering amplitude component in z-axis $(m)$

$R$ - Strain rate $(1 / s)$

$t$ - Thickness of airfoil $(m)$

$\Gamma_{0}$ - Total Circulation $\left(\mathrm{m}^{2} / \mathrm{s}\right)$

$U_{Z R M S}-U_{Z}$ velocity component RMS

$U_{Y R M S}-U_{Y}$ velocity component RMS

$U_{X}-$ Velocity in X-direction $(\mathrm{m} / \mathrm{s})$

$U_{Y}$ - Velocity in Y-direction $(\mathrm{m} / \mathrm{s})$

$U_{Z}$ - Velocity in Z-direction $(\mathrm{m} / \mathrm{s})$

$\Omega$ - Vorticity $(1 / s)$

$r$ - Vortex radius $(m)$

$r_{c}$ - Vortex core radius $(m)$

$b$ - Wingspan $(m)$

$S$ - Wing reference area $\left(m^{2}\right)$

\section{References}

1. Butler, S.F.J., "Aircraft Drag Prediction for Project Appraisal and Performance Estimation," AGARD-CP-124, 1973, pp. 6-1 - 6-50

2. Gunasekaran, Sidaard, Altman, Aaron, "Is There a Relationship Between the Free Shear Layer and the Wingtip Vortex", 54th AIAA Aerospace Science Symposium (SCITECH), January, 2016, San Diego, California. https://doi.org/10.2514/6.2016-1068

3. CGS Aviation, 440 Airport Road Lake Wales, FL. United States. CGS Hawk - http:/ /www.cgsaviation.com/

4. Woopy Company.Woopy Fly Inflatable Wing Aircraft. - http:// fly.woopyjump.com/

5. Feng Zhang, Kevan J. Ghobadi, Grant Spencer, Justin Krofta, Raymond P. LeBeau, Jr.5, Mark McQuilling, "Examination of Three-Dimensional Flow over a Chambered Inflatable Wing", 52nd AIAA Aerospace Science Symposium (SCITECH), January 2014, National Harbor, Maryland. https://doi.org/10.2514/6.2014-0556

6. J.H. McMasters and M.L. Henderson. "Low-speed single element airfoil synthesis." Technical Soaring, 6:1-21, 1980.

7. Walsh, M. J. and Weinstein, L., "Drag and heat-transfer characteristics of small longitudinally ribbed surfaces," AIAA J. 17, 770-771 (1979). https://doi.org/10.2514/3.61216 
8. Viswanath, P. R., “Aircraft viscous drag reduction using riblets," Prog. Aerospace. Sci. 38, 571-600 (2002) https:/ / doi.org/10.1016/S0376-0421(02)00048-9

9. Bechert, D., Hoppe, G., and Reif, W.-E., “On the drag reduction of the shark skin,” AIAA Paper No. 85-0546, 1985.4. [

10. Bechert, D. W., Bruse, M., and Hage, W., “Experiments with three-dimensional riblets as an Idealized model of shark skin," Exp. Fluids 28, 403-412 (2000). https:/ / doi.org/10.1007/s003480050400

11. Walsh, M. J., "Riblets," in Viscous Drag Reduction in Boundary Layers, edited by D. M. Bushnell (AIAA, 1990), Vol. 1, pp. 203-261.

12. Lee S.-J., Lee S.-H. (2001) Flow field analysis of a turbulent boundary layer over a riblet surface. Exp. Fluids 30:153-166https:/ / doi.org/10.1007/s003480000150

13. Raayai-Ardakani, Shabnam, and Gareth H. McKinley. "Drag reduction using wrinkled surfaces in high Reynolds number laminar boundary layer flows." Physics of Fluids 29, no. 9 (2017): 093605. https://doi.org/10.1063/1.4995566

14. G. K. Batchelor (1964). "Axial flow in trailing line vortices". Journal of Fluid Mechanics, 20, pp 645-658 https://doi.org/10.1017/S0022112064001446 